\title{
FOCAL CORTICAL DYSPLASIA PRESENTED WITH STROKE
}

\author{
MD. MAIN UDDIN ${ }^{1}$, FAZLE RABBI MOHAMMED ${ }^{2}$, FAZLE RABBI CHOWDHURY ${ }^{3}$, ABDUR RAHIM ${ }^{4}$
}

\section{Introduction:}

Since the original description by Taylor, ${ }^{1}$ the term focal cortical dysplasia (FCD) has been used to refer to a wide range of alterations of the cortical mantle. The final organization of the cortical mantle is the result of a series of partially overlapping prenatal developmental processes. Perturbation of proliferation of undifferentiated cells in the neuroepithelium, migration of neuroblasts and cell differentiation, as a result of genetic defect or noxious environmental influences, usually results in malformations which are associated with neurological defects, cognitive deficits and particularly epilepsy. ${ }^{1,2}$ This is a case report of focal cortical dysplasia in association with stroke and simple partial seizure which has probably been reported for the first time in Bangladesh.

\section{Case Report:}

A 38 years old, diabetic, normotensive, smoker, righthanded male working in a national security force, Dhaka, was admitted into the Department of Neurology, BIRDEM hospital on 16 January, 2006 with the complaints of right sided weakness and slurring of speech for three weeks. He got admitted to a hospital on the day of his illness and was diagnosed as a case of stroke with right sided hemiparesis and type 2 DM.CT scan of brain was not done. For his uncontrolled blood glucose level he was referred to BIRDEM hospital.

On admission, his pulse rate was $80 \mathrm{~b} / \mathrm{m}, \mathrm{BP} 160 / 100$ mmHg. He had slurred speech and GCS score was 11. He had upper motor type of right sided Facial nerve palsy and muscle power was grade 3 (MRC scale) on right side. Weakness recognized in both proximal and distal group of muscle and right sided planter response was extensor. Other clinical findings were unremarkable.

His random blood glucose level was $28 \mathrm{mmol} / \mathrm{l}$.CT scan of brain was done on the day of admission, but it was inconclusive as to the nature of brain lesion. Other relevant investigations were normal. An MRI of brain was planned but patient suddenly developed simple partial seizure, which was treated with carbamazepine. Eventually MRI of brain was done and focal cortical dysplasia with small cerebral infarct in left parietal lobe was reported [Fig 1(a), (b)]. He was discharged on 24 January, 2006 with carbamazepine, aspirin, insulin, amlodipine and advised for physiotherapy and also to quit smoking.

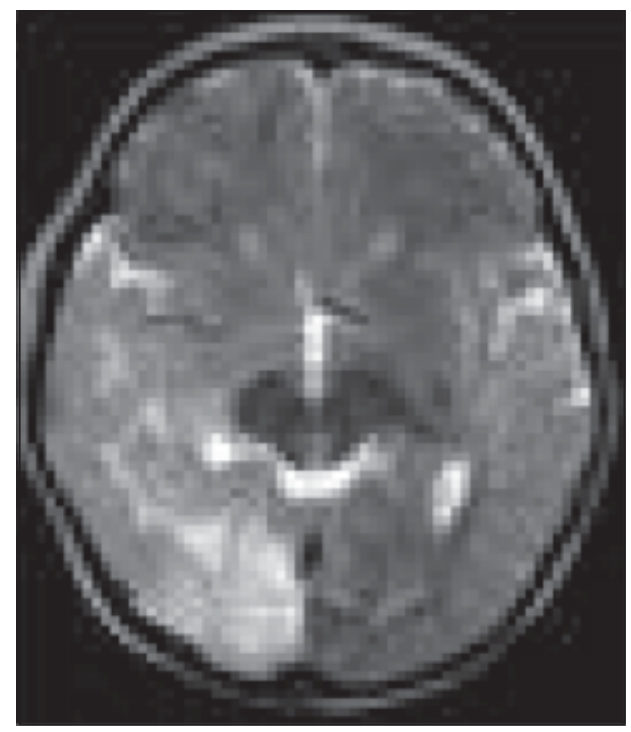

Fig. 1 (a)Cortical dysplasia, MRI view

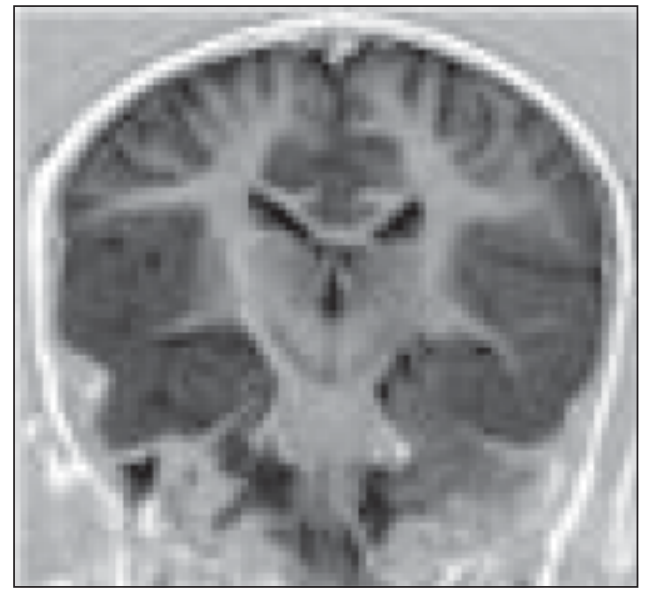

Fig.1 (b) Cortical dysplasia, MRI view

1. Indoor Medical Officer (Neurology), BIRDEM, Dhaka.

2. Post Graduate Trainee, Department of Medicine, Dhaka Medical College Hospital

3. Post Graduate Trainee, Department of Medicine, Dhaka Medical College Hospital

4. Post Graduate Trainee, Department of Medicine, Dhaka Medical College Hospital 


\section{Discussion:}

Cortical dysplasia is a group of developmental defect due to abnormal morphogenesis or defect in the regional specification of neuroepithelium or defect in apoptosis. There is a great deal of interest in the interaction of environmental and genetic defect in the development of cortex. ${ }^{3}$ Although aberrant cortical lamination had been described in epilepsy patients in the past, FCD was not extensively studied until Taylor, et al., ${ }^{1}$ in 1971 described a series of 10 epileptic patients with various degrees of cortical dysplasia. The characteristic balloon cells in these lesions were first described in this report. ${ }^{4}$ Focal cortical dysplasias are part of an array of disorders described variously as disorders of cortical development, cortical dysplasias, cortical dysgenesis, or neuronal migration disorders. ${ }^{5}$ Histological findings in cortical dysplasia include architectural abnormalities such as cortical laminar disorganization and columnar disorganization. More severe forms of FCD are characterized by the presence of abnormal neuronal elements, such as immature neurons, dysmorphic neurons, giant cells and balloon cells. Immature neurons are round homogeneous cells with large nuclei. ${ }^{5}$ Dysmorphic neurons have distorted cell body, axon, and dendrite morphology caused by the accumulation of neurofilaments within the cytoplasm. ${ }^{6,7}$ Giant cells are increased in size but are normal in shape and do not show an accumulation of neurofilaments. ${ }^{1,5}$ Balloon cells are considered a hallmark of FCD, although they are not present in all patients with FCD. Incase of our patient, we did not go for histopathology. Balloon cell was first described by Taylor, et al. ${ }^{1}$ These cells have an eosinophilic cytoplasm and an eccentric nucleus. ${ }^{5-7}$

A panel of epileptologists and neuropathologists devised a classification scheme ${ }^{5}$ in 2004 according to pathological feature that has been widely adopted. They distinguished two types of dysplasia based on the presence or absence of dysmorphic neurons or balloon cells. In Type I FCD, there are no dysmorphic neurons or balloon cells. In Type IA, isolated architectural abnormalities, usually laminar or columnar disorganization, are found. Type IB is also characterized by architectural abnormalities, but giant cells or immature neurons are also seen. It is important to note that no abnormal cells are present in Type I FCD. On the other hand, abnormal neurons are found in type II FCD. In Type IIA, there are dysmorphic cells but no balloon cells. In Type IIB, both dysmorphic cells and balloon cells are found.

Clinical presentations of cortical dysplasia depend on type of lesion. Small focal lesion usually remain asymptomatic, may present with focal seizure as it happened in case of our patient. Diffuse cortical dysplasia may present with developmental delay, static encephalopathy ${ }^{8}$ or severe seizure. So, sometime patient may present with features of stroke without any obvious findings in CT scan. In that case, MRI should be done to reach in a conclusive diagnosis.

\section{References:}

1. Taylor DC, Falconer MA, Bruton CJ, et al. Focal dysplasia of the cerebral cortex in epilepsy. J Neurol Neurosurg Psychiatry 1971; 34:369-387.

2. Tassi L, NColombo N, Garbelli R, Francione S, et al. Focal cortical dysplasia: neuropathological subtypes, EEG, neuroimaging and surgical outcome. Brain 2002; 125, 1719-32.

3. David Chadwik. Disorders of cortical development. In: Michael Donaghy, editor. Brain's Diseases of the Nervous System. New York: Oxford University Press, 2001: 679-81.

4. Wang VY, Chang EF, Barbaro NM. Focal cortical dysplasia: a review of pathological features, genetics, and surgical outcome. Neurosurg Focus 2006; 20 (1):E7

5. Palmini A, Najm I, Avanzini G, et al. Terminology and classification of the cortical dysplasias. Neurology 2004; 62:S2-S8.

6. Spreafico R, Battaglia G, Arcelli P, et al. Cortical dysplasia: an immunocytochemical study of three patients. Neurology 1998; 50:27-36.

7. Spreafico R, Pasquier B, Minotti L, et al. Immunocytochemical investigation on dysplastic human tissue from epileptic patients. Epilepsy Res 1998; 32:34-48.

8. Kuzniecky RI, Jackson G. Neuroimaging in epilepsy. In: Magnetic resonance imaging in epilepsy. New York: Raven Press, 1995: 27-48. 